\title{
CORRESPONDENCE
}

\section{Electrical activity associated with the Blackwell-Udall tornado}

By B. Vonnegut and C. B. Moore

Arthur D. Litlle, Inc., 30 Memorial Drive, Cambridge 42, Mass. 18 July 1956 and 16 August 1956

In his recent article ${ }^{1}$ describing electrical field measurements made near the Blackwell-Udall tornado, Dr. Gunn concludes that "there is little evidence suggesting that the electrical effects near the funnel differ basically from ordinary thunderstorm electrification," and that he "does not see much evidence pointing to the conclusion that the tornado is primarily an electrical phenomenon." As advocates of the classical idea that tornadoes are a manifestation of thunderstorm electricity $2,3,4,5$, we wish to call attention to other electrical observations that were made on the same storm, to comment on Dr. Gunn's conclusions, and to suggest alternative explanations of his interesting data.

First of all, we should emphasize that while we believe that the electrical effects in tornado storms are a great deal more severe than in ordinary thunderstorms, we do not believe that they are basically different. We believe that the electrical charging rates in tornado storms are many times greater than in ordinary ones, and that there is sufficient electrical energy to power a tornado. Because of their extraordinarily intense electrification, we believe that such storms can produce electrical discharges of an intensity and character unknown in common storms.

One of us has suggested that thunderstorm electrification is produced by the convective movements of large volumes of air, and that the electrical energy produced in this way can cause the locally intense winds of the tornado. ${ }^{6} \mathrm{We}$, therefore, share Dr. Gunn's opinion that "the electrical behavior exhibited in fig. 2 is probably what would be expected in ordinary thunderstorms if the turbulent velocity were increased by an order of magnitude."

Although Dr. Gunn's data indicate that the

\footnotetext{
${ }^{1} \mathrm{R}$. Gunn, "Electric field intensity at the ground under active thunderstorms and tornadoes," J. Meteor., 13, 269-273, 1956.

${ }^{2}$ C. T. Lucretius, De rexum natura. (circa 60 B.C., metrical translation by W. E. Leonard, vol. 6), New York, E. P. Dutton, Inc., 260 pp., 1950.

3 F. Bacon, "Natural history of winds - Extraordinary winds and sudden blasts," The works of Francis Bacon. (Vol. 3), Philadelphia, Carey and Hart, 449 pp., 1844.

"R. Hate, "On the causes of the tornado or waterspout," Amer. J. Sci. Arts, 32, 153-161, 1837.

J J. C. A. Peltier,, (translation by R. Hare), Amer. $J$.

Sci. Arts, 38, 73-86, 1840." thunderstorm electricity," Geophys. Res. Pap., No. 42, 169-181,
} 1955.
Blackwell-Udall storm had vigorous electrical activity, it is worth citing additional corroborative data. During the course of this storm, Jones ${ }^{7}$ made sferics measurements at Stillwater, Oklahoma, of the azimuth and repetition rate of the lightning strokes. He reports that, on the bearing of the tornado during its progress, lightning strokes were occurring at a rate ranging from 2 to 25 per second. Dr. Gunn ${ }^{8}$ has cited, as examples of very active storms, one that gave a stroke every $5 \mathrm{sec}$ and another that gave a stroke every $2 \mathrm{sec}$. If the frequency of lightning strokes as determined by Jones is an index of electrical activity, the Blackwell storm was from four to forty times as active as those that have been previously described by Dr. Gunn.

Eyewitnesses to the tornado in Blackwell also have reported evidence of intense electrical activity. Montgomery, who viewed the tornado from a distance of about $3000 \mathrm{ft}$, reports: "As the storm was directly east of me, the fire up near the top of the funnel looked like a child's Fourth of July pin wheel."' "There were rapidly rotating clouds passing in front of the top of the funnel. These clouds were illuminated only by the luminous band of light. The light would grow dim when these clouds were in front, and then it would grow bright again as I could see between the clouds. As near as I can explain, I would say that the light was the same color as an electric arc welder but very much brighter. The light was so intense that I had to look away when there were no clouds in front of it. The light and the clouds seemed to be turning to the right like a beacon in a lighthouse."

Montgomery also tells of other eyewitnesses who had different views of the phenomenon, such as Mrs. Carl Sjoberg whose house in the direct path was completely demolished: "She saw lightning coming up from the ground two or three feet high and about half as wide as adding machine tape. It was a deep blue and forked on the end like a ' $\mathrm{Y}$ ' or like a snake's tongue." 10

According to Montgomery ${ }^{11}$, Lee Hunter, who was $4 \mathrm{mi}$ north of Blackwell, described the tornado as follows: "The funnel from the cloud to the ground was lit up. It was a steady, deep blue light - very

${ }^{7}$ H. L. Jones, Research on tornado identification. (3rd quart. Prog. Rep., Contract No. DA 36-039 SC 64436), Stillwater, Okla. A. and M. College, 8-35, 1955.

8 . Gunn, "Electric-field regeneration in thunderstorms," $J$. Meteor., 2, 136-137, 1954.

'F. C. Montgomery, "Tornadoes at Blackwell, Oklahoma," Mon. Wea. Rev., 83, 109, 1955.

10 F. C. Montgomery, "Some observations on the tornado at Blackwell, Oklahoma, 25 May 1955," Weatherwise, 9, 97 and $101,1956$.

i' Personal communication. 
bright. It had an orange color fire in the center from the cloud to the ground. As it came along my field, it took a swath about 100 yards wide. As it swung from left to right, it looked like a giant neon tube in the air, or a flagman at a railroad crossing. As it swung along the ground level, the orange fire or electricity would gush out from the bottom of the funnel, and the updraft would take it up in the air causing a terrific light - and it was gone! As it swung to the other side, the orange fire would flare up and do the same."

From these and similar accounts ${ }^{12,13}$ of the luminous discharges in tornadoes, it appears that large electric fields and current densities exist in the-interior of the funnel and on the ground directly beneath it. The intense electrical phenomena on the ground are apparently very localized and do not extend for any distance from the funnel.

From the map showing the position of Dr. Gunn's closest stations, Nos. 1 and 2, and from the U. S. Weather Bureau map of the tornado path as determined by Staats and Turrentine ${ }^{14}$, (see fig. 1), it appears that the tornado did not come within $2 \mathrm{mi}$ of the network. Since the intense electrical fields on the ground probably extend no more than a few hundred yards from the funnel, it is not surprising that only relatively weak fields were observed at Dr. Gunn's closest station.

Dr. Gunn observes that the determination of the exact electrical behavior within the clouds is difficult because of the complexity of the electrical activity and the magnitude of the field changes near the tornado. Interpretation of his data is further complicated by the probability that the response of his measuring apparatus is far too slow to follow the rapid field

${ }^{12}$ C. Flammarion, The atmosphere. New York, Harper Bros., $339-347,1873$.

${ }^{13}$ R. S. Hall, "Inside a Texas tornado," Weatherwise, 4, 54-57, 1951.

${ }_{14}$ Accepted for publication in Bull. Amer. meteor. Soc.

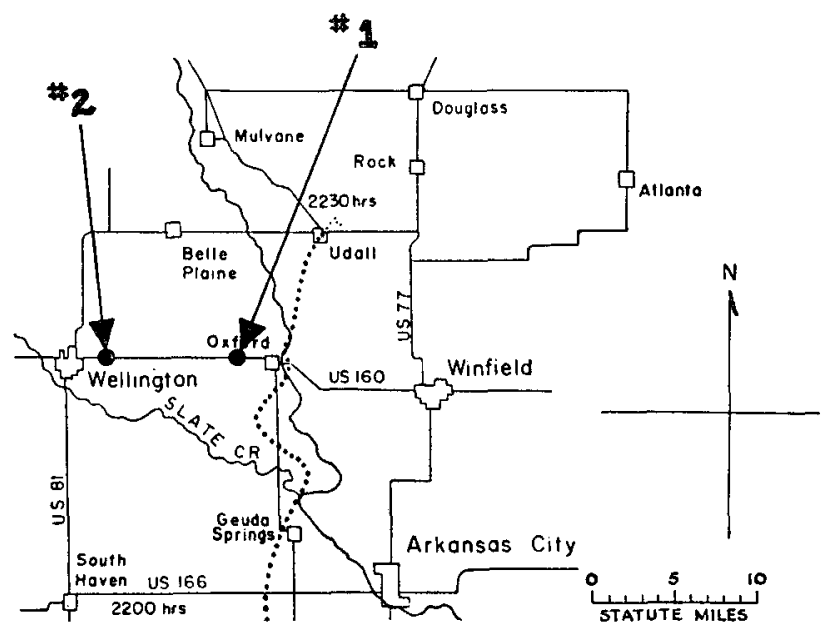

FIG. 1. Tornado path and station locations. fluctuations that occur in the tornado storm. Jones' sferics measurements indicate electric discharges during the Blackwell tornado occurred at a rate of greater than $20 \mathrm{sec}^{-1}$. Dr. Gunn's apparatus, which he states has a response time of approximately $1 \mathrm{sec}$, would be incapable of responding to such rapid variations of the electric field.

While it appears doubtful that Dr. Gunn's apparatus could resolve the rapid field changes in the storms, it seems probable that his records may provide an average picture of the electric field. It is possibly significant that his stations which were nearest to the tornado show appreciably lower and smoother values of the field during the tornado's closest approach. Both Dr. Gunn's field record and the reports of eyewitnesses indicate that there is a reduction of cloud-to-ground discharges for some distance around the tornado. Such observations support Peltier's suggestion ${ }^{5}$ that the tornado serves as a preferred conducting path for electricity. It is possible that the continuous flow of charge in the tornado, indicated by its steady luminosity, may suppress the electric field at the ground and cloudto-ground lightning for some distance from the funnel.

Certainly at present we do not have sufficient scientific information to determine what is the role of electricity in the tornado. The interesting observations supplied by Dr. Gunn should provide stimulus for further studies of the electrical activity associated with these storms. In our opinion, such studies should include the following efforts:

1. Determination of the sign and magnitude of the electric field and point-discharge current directly beneath the tornado funnel;

2. Measurement of electric fields near the tornado with instruments having a time of response of the order of $0.01 \mathrm{sec}$ or less; and

3. Determination of the nature of the electrical phenomena commonly observed at night within and beneath the tornado funnel. 